\title{
FERMENTATIVE PROCESSES OF THE FUSIFORM BACTERIA
}

\author{
HELEN C. JACKINS AND H. A. BARKER \\ Division of Plant Biochemistry, University of California, Berkeley, California
}

Received for publication October 21, 1950

Information regarding the fusiform bacteria has been slow to accumulate largely because of the difficulty of growing and maintaining these obligate anaerobes. Previous investigations have been concerned mainly with the possible role of these bacteria in human disease. Taxonomic studies have shown something of the morphology and rudimentary biochemical properties of the organisms, but there has been no study of their fermentative activities.

This investigation was undertaken for the purpose of determining the basic fermentative patterns of the fusiform bacteria. It was hoped that such an investigation, in addition to revealing the main metabolic processes and allowing a comparison of these organisms with other fermentative bacteria, would be an aid in the taxonomic treatment of the group.

\section{HISTORICAL REVIEW}

The taxonomy of the fusiform bacteria is somewhat confused and therefore it seems desirable to review enough of the literature dealing with this group to clarify the relation of the bacteria we have used to those studied by previous investigators. At the same time we shall summarize the available information concerning the physiology and biochemistry of the group.

Knorr (1922) proposed the generic name Fusobacterium and defined three species, $F$. plauti-vincenti, $F$. nucleatum, and $F$. polymorphum. All were described as gram-negative, nonsporeforming, obligately anaerobic rods with pointed ends. These three species were differentiated by the size and arrangement of their cells, by colonial appearance, by their ability to grow in meat broth with or without added serum, and by the amount of acid they produced during growth in sugar-containing media. Unfortunately Knorr did not conduct extensive biochemical tests on his strains. A sugar fermentation pattern would be of considerable aid in identifying his strains with those described by other investigators. Some of the biochemical characteristics he described are at variance with those reported more recently for organisms fulfilling his morphological criteria. He reported no indole or hydrogen sulfide production by any of his strains. Other investigators have shown that organisms of the $F$. polymorphum and $F$. nucleatum type usually produce both hydrogen sulfide and indole. Organisms of the $F$. plauti-vincenti type do not form these compounds.

The production of an unpleasant odor was described by Knorr as a property of all his strains. Varney (1927) has denied that any fusiform bacterium produces an unpleasant odor and reported that this is always the result of contamination. Spaulding and Rettger $(1937 a, b)$ found that an unpleasant odor is produced by organisms possibly corresponding to $F$. nucleatum Knorr and $F$. polymor- 
phum Knorr but not by organisms of the $F$. plauti-vincenti Knorr group. In the fifth (1939) edition of Bergey's Manual (Breed et al., 1948), F. nucleatum is described as odoriferous, but $F$. polymorphum and $F$. plauti-vincenti are described as odor-free.

The classification of the fusiform bacteria that is given in the fourth edition of Bergey's Manual (1934) is one devised by Hoelling (1910) using as the type species, Fusiformis termitidis, a spindle-shaped, gram-negative, anaerobic rod found in the intestine of termites. Fusiformis dentium Hoelling is described as the organism found in Vincent's angina and is described as gram-positive. Included in the genus Fusiformis Hoelling were Fusiformis nucleatus Knorr and polymorphus Knorr.

The fifth edition of Bergey's Manual (1939) drops Fusiformis termitidis as a poorly defined species and uses Fusobacterium as the generic name for this group. This genus includes only gram-negative forms. The organism of Vincent's angina, $F$. plauti-vincenti, is now described as gram-negative. Included in this genus, with the three species described by Knorr, is Fusobacterium biacutum, an organism isolated from inflamed appendices by Weinberg and Prévot (1926) and described as a gram-negative, spindle-shaped, nonsporulating anaerobic rod, which produces abundant gas in ordinary media. The other fusiform bacteria do not produce visible gas. The description of the organism of Weinberg and Prévot leads one to the conclusion that it could be included in the genus Bacteroides as described by Weiss and Rettger (1937).

Varney (1927) studied a large number of strains of fusiform bacteria both morphologically and serologically and classified the group into four types. The lack of biochemical data to correlate with his description of the colonial and cellular morphology of the different serological types makes it difficult to compare his classification with those of other workers.

Slanetz and Rettger (1933) divided 53 strains of fusiform bacteria into four types on the basis of cellular and colonial morphology, fermentative ability, and other biochemical characteristics. Spaulding and Rettger (1937a) increased the number of biochemical taxonomic criteria and rearranged the Slanetz and Rettger classification so that two main groups of fusiform bacteria were formed: group I, those organisms fermenting only glucose or only glucose and sucrose with the production of little acidity, producing indole and hydrogen sulfide, and reducing nitrate; and group II, those organisms fermenting maltose and sometimes lactose in addition to glucose and sucrose with the production of relatively great acidity, but not producing indole and hydrogen sulfide or reducing nitrate.

$F$. plauti-vincenti Knorr clearly corresponds to Spaulding and Rettger's group II. F. polymorphum Knorr probably corresponds to Spaulding and Rettger's group I, and $F$. nucleatum Knorr seems to correspond to group I.

Boe (1941) proposed that organisms corresponding to $F$. plauti-vincenti Knorr, group II Spaulding and Rettger, be placed in the genus Leptotrichia. He has reported that these organisms are distinctly gram-positive in young cultures but that gram-negative elements appear very early. He believes that the character- 
istics of these organisms conform to those described for Leptotrichia buccalis Trevisan. Boe suggests that there is only one species of fusiform bacterium, that one producing relatively little acidity in sugar media and producing a foul odor, since only minor differences in cellular and colonial morphology were observed between a large number of strains. This species he calls $F$. plauti-vincenti although plauti-vincenti is the specific epithet given by Knorr to the large-celled type that produces comparatively more acid in sugar media.

Topley and Wilson (1946) use the name Fusiformis fusiformis for the type species of the genus of fusiform bacteria and refer to it as the organism implicated in Vincent's angina. $F$. fusiformis corresponds very well to $F$. plautivincenti Knorr and to group II of Spaulding and Rettger. Topley and Wilson include in the genus Fusiformis the agent of calf diphtheria, placed in the genus Spherophorus in the sixth edition of Bergey's Manual (1948), and also several gram-negative, nonsporulating anaerobes isolated from the appendix (Fusiformis serpens, Fusiformis fragilis, and Fusiformis furcosus). The relationship of the gram-negative, nonsporeforming rods that are inhabitants of the intestine to those that are mouth inhabitants is not clear. Many of the organisms from the intestine also possess a fusiform shape and on this basis have been placed with the fusiform bacteria of the mouth (Weinberg and Prévot, 1926).

The fusiform bacteria of the mouth have been divided, then, into three species by Knorr (1922), into two major groups by Spaulding and Rettger (1937), and into two separate genera by Boe (1941). Fusobacterium nucleatum Knorr and Fusobacterium polymorphum Knorr correspond to group I of Spaulding and Rettger and to the organism called $F$. plauti-vincenti by Boe. Fusobacterium plauti-vincenti Knorr corresponds to group II of Spaulding and Rettger and to the organism called Leptotrichia buccalis Trevisan by Boe.

The fusiform bacteria of the mouth are all nonsporeforming rods with pointed ends. The gram reaction of $F$. plauti-vincenti Knorr has been disputed, but the other fusiform bacteria have been consistently described as gram-negative.

These bacteria are all obligate anaerobes. Knorr (1922) grew $F$. polymorphum in a meat infusion medium and $F$. plauti-vincenti in a meat infusion serum medium. Spaulding and Rettger (1937b) found that ordinary meat extract cysteine broth would support the growth of type I organisms but that the addition of a fermentable carbohydrate was necessary for vigorous growth of the type II organisms.

Little is known of the fermentative activities of the fusiform bacteria. $F$. nucleatum Knorr and $F$. polymorphum Knorr, type I Spaulding and Rettger, ferment glucose or glucose and sucrose with the production of relatively little acidity, reduce nitrates, and produce indole and hydrogen sulfide. These organisms produce a foul odor. F. plauti-vincenti Knorr, type II of Spaulding and Rettger, ferments maltose or maltose and lactose in addition to glucose and sucrose with the production of greater acidity, does not reduce nitrates, and produces neither indole nor hydrogen sulfide. These organisms do not produce a foul odor. None of the fusiform bacteria of the mouth have been reported to produce visible gas. 


\section{MATERIALS AND METHODS}

Seven strains of obligately anaerobic, gram-negative, nonsporulating rods with pointed ends were isolated from normal healthy mouths according to the isolation procedures described by Spaulding and Rettger (1937a). The medium used for primary isolation contained 1 per cent Difco peptone, 0.3 per cent Difco meat extract, 0.5 per cent Difco yeast extract, 0.1 per cent glucose, 0.05 per cent sodium thioglycolate, $5 \times 10^{-5}$ per cent crystal violet, and 2 per cent agar.

Three of the strains, DB6, FA1, and HJN, could best be identified with Fusobacterium nucleatum Knorr (1922) and group I of Spaulding and Rettger (1937a). These strains produce a foul odor in a meat extract, yeast extract medium, ferment glucose and sucrose (producing a terminal $\mathrm{pH}$ of 6.2) but not lactose or maltose, produce indole and hydrogen sulfide, and reduce nitrates. The cells are 4 to 6 microns in length and 0.5 to 0.75 microns in diameter. They produce slightly irregular colonies 1 to $2 \mathrm{~mm}$ in diameter, exhibiting an occasional outgrowth, a finely granular interior, and a smooth surface broken by fine veinlike markings.

Four of the strains, HJD, MS1, PB1, and LE1, could be identified with Fusobacterium plauti-vincenti Knorr (1922) and group II of Spaulding and Rettger $(1937 a)$. These bacteria do not produce a foul odor; ferment maltose, in addition to glucose and sucrose, producing a terminal $\mathrm{pH}$ of 5.2 ; do not produce indole or hydrogen sulfide; and do not reduce nitrates. The cells are 10 to 12 microns in length and 1 micron in diameter. They produce irregularly shaped colonies about $2 \mathrm{~mm}$ in diameter that exhibit a coarsely curled interior with a somewhat yellowish appearance.

Brewer's thioglycolate medium (Difco) was used to maintain stock cultures, and the same medium, freed of the small amount of agar it contains, was used in the growth experiments. The stock cultures were stored in a refrigerator under a pyrogallol seal. Weekly transfers were necessary to maintain viable cultures.

Anaerobiosis was achieved in the isolation procedures by incubating the plates in an atmosphere of 80 per cent hydrogen and 20 per cent carbon dioxide in the presence of palladinized asbestos. Liquid cultures were grown in volumetric flasks filled to the mark with freshly prepared medium. When the carbon dioxide content of the spent medium was to be determined, the flasks were sealed only with a cotton plug and rubber stopper. Growth occurred within $1 \mathrm{~cm}$ of the surface. In growing bacteria for cell suspension experiments, a pyrogallol and sodium carbonate seal was used.

Cell suspensions were prepared from liquid cultures incubated 24 hours at $37 \mathrm{C}$. The cells were harvested by centrifugation; washed in $\mathrm{m} / 30$ phosphate buffer, $\mathrm{pH} 7.2$, containing 0.01 per cent sodium sulfide; and resuspended to $1 / 50$ the original volume of the same solution. The cell suspensions were used immediately after preparation.

Methods of analysis. Carbon dioxide was determined manometrically by the Warburg technique and by the method of Peters and van Slyke (1932). Ketones were tested for by the addition of 2,4-dinitrophenylhydrazine. Alcohols were determined by a semimicro modification of the method of Northrop (1919). The alcohols were identified by dichromate oxidation to the corresponding acids. 
Total volatile acids were determined by steam distillation and titration. Formic acid was identified and estimated by the method of Friedemann and Haugen (1943). The identification of the higher fatty acids was based upon separation of the individual acids by azeotropic distillation according to the method of Schicktanz et al. (1940) and followed by Duclaux distillation of the pure acids. Quantitative estimation of fatty acids in mixtures was done by the method of Knetemann (1928). Acetylmethylcarbinol and 2,3-butylene glycol were determined qualitatively by the Voges-Proskauer test and quantitatively by the method of Langlykke and Peterson (1937). Glycerol was determined by the method of Feigl and Frehden (1937), total nonvolatile acids by the titration of the 48-hr ether extract of the nonvolatile residue, pyruvate by the bisulfite-binding method of Elliot, Benoy, and Baker (1935), and lactic acid by the method of Friedemann and Graeser (1933). Titration curves of the nonvolatile acids were made to test

TABLE 1

Metabolic products of the fusiform bacteria in Brewer's medium (Quantities expressed in millimoles per liter of medium)

\begin{tabular}{|c|c|c|c|c|c|c|c|}
\hline & \multicolumn{3}{|c|}{ P. NUCLEaTUX } & \multicolumn{4}{|c|}{ F. PLAUTT-VINCENTI } \\
\hline & DB6 & FA1 & HJN & HJD & MS1 & PB1 & LE1 \\
\hline Carbon dioxide........... & 28.0 & 31.5 & 35.0 & $\mathbf{0}$ & 0 & 0 & 0 \\
\hline Ammonia............... & 21.0 & 22.5 & 22.0 & 0 & 0 & 0 & 0 \\
\hline Ethyl alcohol... & 2.5 & 2.5 & 2.0 & 0 & 0 & 0 & 0 \\
\hline Butyl alcohol. . & 2.5 & 2.5 & 2.0 & 0 & 0 & 0 & 0 \\
\hline Acetic acid...... & 12.0 & 17.0 & 15.0 & 7.0 & 5.5 & 5.5 & 5.5 \\
\hline Butyric acid........ & 15.0 & 15.0 & 13.0 & 0 & 0 & 0 & 0 \\
\hline Lactichacid............ & 45.0 & 30.0 & 43.0 & 55.0 & 58.0 & 58.0 & 56.0 \\
\hline
\end{tabular}

for the presence of more than one acidic group. The presence of dicarboxylic acids was excluded in this way since the titration curve of the nonvolatile acid fraction was identical with that for lactic acid. Glucose was determined by the ceric sulfate method of Hassid (1937). Total nitrogen was determined by microKjeldahl digestion using a selenium catalyst, and ammonia by steam distillation from a sodium borate solution and titration with acid.

\section{RESULTS}

The end products of growth metabolism. Brewer's thioglycolate medium (agarfree) was used to determine the catabolic products because it supports good growth of all strains and contains both amino acids and carbohydrates. Cultures were incubated in 500-ml volumetric flasks for 48 hours at $37 \mathrm{C}$. At the end of this period, when the cells had flocculated, the clear supernatant was analyzed. The results, corrected for a blank determination on the uninoculated medium, are given in table 1.

All our strains of Fusobacterium nucleatum show a similar pattern of metabolic products. No insoluble gas is produced but carbon dioxide is formed in appreci- 
able quantity. These organisms produce ammonia, ethyl and butyl alcohols, and acetic, butyric, and lactic acids. Lactic acid, determined directly, accounts very well for the total nonvolatile acid.

All strains of Fusobacterium plauti-vincenti show a markedly different metabolic pattern. These organisms do not produce carbon dioxide, ammonia, or any volatile neutral product. The main product is lactic acid. In addition, a small amount of acetic acid is formed as the only volatile acid.

Thus, the strains of $F$. nucleatum are able to attack the nitrogen-containing constituents of the medium, as evidenced by the production of ammonia, and also to attack glucose as indicated by the decrease in $\mathrm{pH}$ from 7.2 to 6.2 . The strains of $F$. plauti-vincenti evidently are unable to attack nitrogenous compounds since they do not form significant amounts of ammonia. Further evidence of this was obtained from experiments in which attempts were made to grow the organism in a peptone, meat extract, yeast extract medium to which glucose was not added. Only faint turbidity was obtained with a heavy inoculum, whereas massive growth occurred in a sugar-containing medium. The main catabolic activity of $F$. plauti-vincenti is a conversion of glucose to lactic acid, accompanied by a decrease in $\mathrm{pH}$ from 7.2 to 5.4 .

The relationship of glucose fermentation to amino acid fermentation in the growth metabolism of $F$. nucleatum. In order to demonstrate the role of amino acids and of glucose in the growth of the organism, three series of cultures containing different concentrations of glucose were compared during the growth process. One series of four $50-\mathrm{ml}$ volumetric flasks contained a medium consisting of 1 per cent peptone, 0.5 per cent meat extract, 0.5 per cent yeast extract, and 0.05 per cent sodium thioglycolate. The second series contained 0.1 per cent glucose and the third series 0.5 per cent glucose in addition to the basal medium. The cultures were started with the same volume of inoculum, and the turbidity, reducing substances, ammonia content, and $\mathrm{pH}$ were determined after $0,5,15$, and 46 hours of growth at $37 \mathrm{C}$ (table 2).

The data on the turbidity of the cultures at the different intervals of time indicate that both the rate of growth and the total yield of cells are increased by the addition of glucose to the medium. The immediate decrease in $\mathrm{pH}$ and the delayed ammonia production in the media containing sugar indicate that glucose is used preferentially to amino acids by $F$. nucleatum DB6.

The decrease in the reducing power of the medium does not seem to be a true measure of glucose utilization since the reducing values decline very little and very slowly. Evidently other substances capable of reducing alkaline ferricyanide are produced during the growth of the organism.

The dissimilation of pyruvate by Fusobacterium nucleatum DB6. The products of pyruvate fermentation by a cell suspension are mainly carbon dioxide, acetic butyric acid, and lactic acid (table 3). Some alcohol was detected, but the amount was too small to be significant. The ratio of acetic acid to butyric acid varied somewhat in other experiments, but the ratio was always close to 1.5:1. The yield of carbon dioxide in these experiments was somewhat lower than that observed in manometric experiments. 
The dissimilation of glucose by $F$. nucleatum DB6. The rate of glucose fermentation by cell suspensions determined by measuring both carbon dioxide and acid production manometrically was very low, $Q_{\mathrm{co}_{2}}^{\mathrm{N}_{2}}(\mathrm{~N})=47$, and only $20 \mathrm{mg}$ of

TABLE 2

Turbidity, reducing substances, ammonia, and $p H$ changes by $F$. nucleatum DB6 in media containing different concentrations of glucose

\begin{tabular}{l|c|c|c|c|c|c}
\hline & & $0 \mathrm{HR}$ & $5 \mathrm{HR}$ & $15 \mathrm{HR}$ & $21 \mathrm{HR}$ & $46 \mathrm{HR}$ \\
\hline $\begin{array}{l}\text { Turbidity (uninoculated } \\
\text { 0) }\end{array}$ & $\begin{array}{c}\text { Basal medium } \\
\text { plus 0.1\% glucose }\end{array}$ & 30 & 36 & 45 & 45 & 18 \\
& plus 0.5\% glucose & 30 & 46 & 80 & 81 & 42 \\
$\mathrm{pH}$ & Basal medium & 7.2 & 7.1 & 6.9 & 6.9 & 6.7 \\
& plus 0.1\% glucose & 7.2 & 6.8 & 6.3 & 6.2 & 6.2 \\
& plus 0.5\% glucose & 7.2 & 6.5 & 6.1 & 6.0 & 6.0 \\
\hline Ammonia in micromoles/ $/$ & Basal medium & 2 & 10 & 14 & 14 & 17 \\
ml & plus 0.1\% glucose & 2 & 8 & 24 & 24 & 27 \\
& plus 0.5\% glucose & 2 & 8 & 13 & 14 & 21 \\
\hline Reducing substances as & Basal medium & 2.3 & 2.0 & 1.9 & 2.0 & 2.1 \\
glucose in mg/ml & plus 0.1\% glucose & 3.3 & 2.8 & 2.8 & 2.8 & 2.7 \\
& plus 0.5\% glucose & 7.2 & 6.7 & 6.3 & 6.2 & 6.2 \\
\hline
\end{tabular}

TABLE 3

The fermentation of pyruvate and of glucose by $F$. nucleatum DB6

(The fermentations were by washed cells in $\mathrm{M} / 30$ phosphate buffer, $\mathrm{pH} 7.2$, in evacuated Thunberg tubes at $37 \mathrm{C}$. Quantities are corrected for endogenous fermentation and are expressed in millimoles per 100 millimoles of substrate)

\begin{tabular}{|c|c|c|}
\hline & (1.36 mx fermented) & ( $0.103 \mathrm{~m} \mathrm{~m}$ fermented $)$ \\
\hline 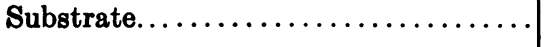 & 100 & 100 \\
\hline 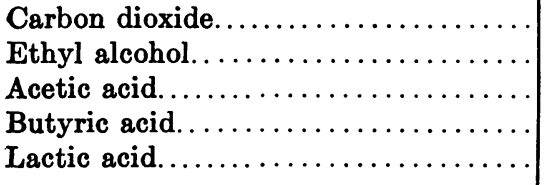 & $\begin{array}{c}65.5 \\
0 \\
30.7 \\
20.5 \\
20.5\end{array}$ & $\begin{array}{l}76 \\
56 \\
26 \\
17 \\
85\end{array}$ \\
\hline 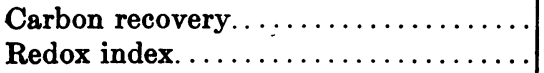 & $\begin{array}{l}94 \% \\
0.95\end{array}$ & $\begin{array}{l}94 \% \\
1.01\end{array}$ \\
\hline
\end{tabular}

glucose were fermented when incubated with a dense cell suspension in a Thunberg tube. The amount of glucose fermented was determined by comparing the reducing value of the cell suspension plus substrate with that of the cell suspension alone; the difference was taken as the value for the residual glucose. The products of the fermentation of glucose are carbon dioxide, acetic acid, butyric 
acid, ethyl alcohol, and lactic acid. The quantitative relationship of the products to the substrate is given in table 3. This fermentation differs from that of the more oxidized substrate, pyruvate, in the relatively large quantities of alcohol formed. This compound is ethyl alcohol since oxidation with dichromate converts it entirely to acetic acid. In this connection it will be recalled that butyl alcohol was found as a product of fermentation in growing cultures of $F$. nucleatum. It is probable that the course of glucose dissimilation by resting and growing cells differs as a result of differences in $\mathrm{pH}$, or other conditions. The $\mathrm{pH}$ is higher in the growth medium because of the formation of ammonia.

\section{TABLE 4}

Carbon dioxide and ammonia production from amino acids by washed cell suspensions of $F$. nucleatum $D B 6$

(One $\mathrm{ml}$ of a cell suspension in $\mathrm{M} / 30$ phosphate buffer, $\mathrm{pH}$ 7.2, was incubated with approximately 20 micromoles of each amino acid in a Warburg vessel in an atmosphere of nitrogen for $2 \mathrm{hr}$ at $37 \mathrm{C}$. The values have been corrected for carbon dioxide and ammonia production by the cell suspension without substrate. The $Q_{\mathrm{co2}}$ values were determined in a separate experiment)

\begin{tabular}{|c|c|c|c|}
\hline SUBSTRATE* & $\begin{array}{c}\mu \mathrm{M} \mathrm{CO}_{2} \\
\text { PER } 10 \mu \mathrm{M} \text { AMINO } \\
\text { ACID ADDED }\end{array}$ & $\begin{array}{l}\text { MM AMMONIA } \\
\text { PER } 10 \text { MM AMTO } \\
\text { ACID ADDED }\end{array}$ & $Q_{\cos }^{N_{2}}(N)$ \\
\hline 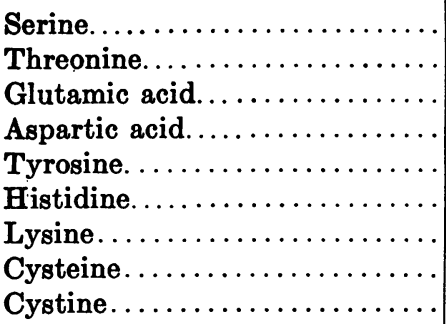 & $\begin{array}{r}8.2 \\
3.5 \\
3.0 \\
1.8 \\
2.9 \\
5.0 \\
1.0 \\
6.0 \\
13.0\end{array}$ & $\begin{array}{c}9.3 \\
4.7 \\
3.0 \\
0.0 \\
3.0 \\
15.0 \dagger \\
10.0 \dagger \\
7.0 \\
18.0\end{array}$ & $\begin{array}{r}132 \\
85 \\
73 \\
25 \\
70 \\
106 \\
- \\
130 \\
280\end{array}$ \\
\hline
\end{tabular}

* The following substrates gave no $\mathrm{CO}_{2}$ or $\mathrm{NH}_{3}$ : proline, valine, leucine, norleucine, alanine, and glycine. Arginine, tryptophan, hydroxyproline, and phenylalanine gave little or no ammonia; $\mathrm{CO}_{2}$ production was not tested.

$\dagger$ After 9 hours' incubation in a separate experiment, histidine and lysine yielded 17 and $15 \mu \mathrm{M} \mathrm{NH}$, respectively.

The fermentation of amino acids by $F$. nucleatum DB6. The production of ammonia from a complete medium by the growing culture of $F$. nucleatum indicates that this organism dissimilates amino acids. The amino acid dissimilation was further investigated using three approaches: firstly, a determination of the amino acids fermented; secondly, a study of the occurrence of the Stickland reaction, the decomposition of pairs of different amino acids; and, lastly, an analysis of the metabolic products formed from some of the amino acids that are metabolized most rapidly.

The fermentability of the amino acids was investigated by incubating washed cell suspensions of strain DB6 with individual amino acids in a Warburg vessel and determining the carbon dioxide and ammonia produced (table 4).

The results indicate that $F$. nucleatum DB6 is able to dissimilate serine, 
threonine, glutamic acid, aspartic acid, tyrosine, histidine, lysine, cysteine, and cystine when these amino acids are incubated individually with the cell suspension. $F$. nucleatum $\mathrm{DB} 6$ does not decompose glycine, alanine, leucine, valine, norleucine, proline, hydroxyproline, arginine, tryptophan, or phenylalanine at a significant rate when these acids are provided singly or together in a mixture. Methylene blue reduction tests indicated that these refractory amino acids cannot act as hydrogen donors.

The possibility that the refractory amino acids might enter into a paired fermentation with other amino acids or other metabolites was considered. This possibility was investigated by incubating cell suspensions of $F$. nucleatum DB6 with mixtures of the refractory amino acids and serine, refractory amino acids and glutamic acid, and refractory amino acids and glucose. In no instance did the fermentable substance activate the decomposition of the refractory amino acids as indicated by carbon dioxide or ammonia production.

Most of the amino acids yielded approximately equivalent amounts of carbon dioxide and ammonia during 2 hours' incubation with a cell suspension (table 4). However, several amino acids gave $\mathrm{CO}_{2}: \mathrm{NH}_{3}$ ratios much greater or smaller than unity. The dissimilation of aspartic acid appears to involve a slow decarboxylation without deamination. The dissimilation of lysine, on the contrary, seems to involve deamination without much decarboxylation. The deamination of one amino group proceeds at a rate comparable to that of serine, whereas the second amino group is more slowly split off. It is not known which amino group is removed first. One attempt to demonstrate an alpha-keto acid as the product of lysine deamination by the bisulfite-binding method was negative. The high yield of ammonia in the histidine fermentation indicates that the imidazole ring is attacked in addition to the alpha-amino group.

The end products of serine and glutamic acid fermentation by $F$. nucleatum DB6. As might be expected, the products of the fermentation of serine are similar to those derived from pyruvate except for the additional occurrence of ammonia and ethyl alcohol (table 5). Alcohol partially replaces the lactic acid of the pyruvate fermentation as a reduced product. Consequently the yield of carbon dioxide is raised.

The products of the fermentation of glutamic acid were found to be carbon dioxide, ammonia, acetic acid, butyric acid, and lactic acid (table 5). Formic acid was detected in trace amounts, less than 4 per cent of the total volatile acids.

The fermentation of pyruvate and glucose by F. plauti-vincenti HJD. Carbon dioxide, formic acid, acetic acid, and lactic acid were identified as products of pyruvate fermentation by cell suspensions of $F$. plauti-vincenti (table 6). The low carbon recovery shows that not all of the products were accounted for, but repeated attempts to detect other compounds or to find larger amounts of the known products were unsuccessful. Fermentations were initiated at $\mathrm{pH} 8.0$ as well as pH 7.2 in anticipation that the shift toward alkalinity might alter the fermentative pattern in a manner similar to that observed with the lactic acid bacteria. However, no significant differences were apparent between the fermentations initiated at the different hydrogen ion concentrations. 
Lactic acid was the only product formed from glucose (table 6). No volatile neutral products were detected; carbon dioxide and volatile acid production in

\section{TABLE 5}

The fermentation of serine and glutamic acid by washed cell suspensions of F. nucleatum DB6 (One $\mathrm{ml}$ of a washed cell suspension in $\mathrm{M} / 30$ phosphate buffer, $\mathrm{pH} 7.2$, was incubated with the substrate in a Warburg vessel in an atmosphere of nitrogen at $37 \mathrm{C}$. Incubation was continued until carbon dioxide evolution ceased and the substrate was completely decomposed. The quantities are expressed in micromoles and are corrected for endogenous fermentation)

\begin{tabular}{|c|c|c|}
\hline & $\begin{array}{l}\text { Sxrive } \\
\left.\text { (37 } \mu \text { re fermented }{ }^{*}\right)\end{array}$ & $\begin{array}{l}\text { GLUTAMac ACD } \\
\text { (58 } \mu \mathrm{M} \text { fermented })\end{array}$ \\
\hline 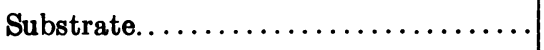 & $(100)^{*}$ & $(100)^{*}$ \\
\hline 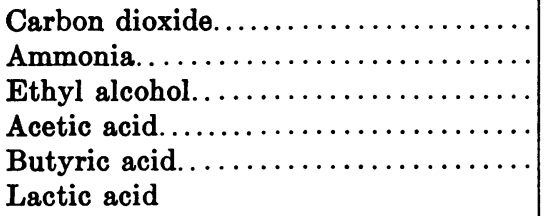 & $\begin{array}{r}91 \\
100 \\
19.0 \\
25.7 \\
25.7 \\
8.1\end{array}$ & $\begin{array}{r}102 \\
100 \\
0 \\
96 \\
48 \\
14\end{array}$ \\
\hline $\begin{array}{l}\text { Carbon recovery } \ldots \ldots \ldots \ldots \ldots \ldots \ldots \ldots \ldots \\
\text { Redox index } \ldots \ldots \ldots \ldots \ldots \ldots \ldots \ldots\end{array}$ & $\begin{array}{r}102 \% \\
1.03\end{array}$ & $\begin{array}{l}105 \% \\
0.97\end{array}$ \\
\hline
\end{tabular}

* Calculated from the ammonia produced.

TABLE 6

The fermentation of pyruvate and of glucose by washed cell suspensions of $F$. plauti-vincenti HJD

(One $\mathrm{ml}$ of a washed cell suspension in $\mathrm{M} / 30$ phosphate buffer, $\mathrm{pH} 7.2$, was incubated with the substrate in an evacuated Thunberg tube at $37 \mathrm{C}$. The quantities are expressed in micromoles and have been corrected for endogenous fermentation)

\begin{tabular}{|c|c|c|}
\hline & $\begin{array}{c}\text { PYROVaTE } \\
\text { (355 } \mu \mathrm{M} \text { fermented) }\end{array}$ & $\begin{array}{c}\text { GLocosi } \\
\text { (111 } \mu \mathrm{M} \text { fermented) }\end{array}$ \\
\hline 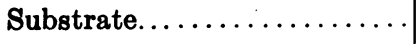 & 100 & 100 \\
\hline $\begin{array}{l}\text { Carbon } \operatorname{dioxide} \ldots \ldots \ldots \ldots \ldots \\
\text { Formic acid. } \ldots \ldots \ldots \ldots \ldots \ldots \ldots \\
\text { Acetic acid. } \ldots \ldots \ldots \ldots \ldots \ldots \\
\text { Lactic acid } \ldots \ldots \ldots \ldots \ldots \ldots\end{array}$ & $\begin{array}{r}19 \\
40 \\
64 \\
6\end{array}$ & $\begin{array}{r}0.0 \\
0.0 \\
0.0 \\
164\end{array}$ \\
\hline Carbon recovery........... & $68 \%$ & $82 \%$ \\
\hline
\end{tabular}

the cell suspension plus glucose was significantly less than in the cell suspension alone. All of the nonvolatile acid was accounted for as lactic acid.

The low carbon recovery in this fermentation was consistent over several experiments. The most likely explanation for this phenomenon is fermentative assimilation, in which a portion of the glucose utilized by the organism is trans- 
formed into cell material and hence does not appear as a soluble end product in the medium.

The gram reaction of $F$. plauti-vincenti $H J D$. Since the type of metabolism exhibited by strain HJD is typical of the homofermentative lactic acid bacteria, which are, however, characteristically gram-positive, and since the gram reaction of $F$. plauti-vincenti has been disputed (Boe, 1941), it was decided to reinvestigate the gram-reaction of our strain of this organism in order to determine more exactly its similarity or dissimilarity to the lactic acid bacteria.

An attempt was made to demonstrate gram-positiveness in young cells of strain HJD because it is well known that the gram-positive character of many bacteria is lost in old cultures. First, cells from plates incubated for 20 hours at $37 \mathrm{C}$ were examined by standard methods of gram staining. On these plates there were distinct colonies, barely visible to the naked eye but easily picked under the dissecting microscope. The cells were clearly gram-negative. Next, cells from plates 12 hours old were examined. It was not feasible to attempt to pick up material from these plates since the colonies were very small. Preparations were made by the method of the cover slip impression. These cells were also gram-negative. Finally, the plates were examined after only 6 hours' incubation. The preparations made by cover slip impression showed many definitely gram-positive cells, although gram-negative cells were in evidence. Thus, it appears that our strain of $F$. plauti-vincenti Knorr is actually gram-positive in the very early stages of development but becomes completely gram-negative before the population has increased to the point at which observations would ordinarily be made.

Parallel observations were made on $F$. nucleatum DB6. This organism always appeared to be gram-negative.

Catalase activity. Both $F$. nucleatum DB6 and $F$. plauti-vincenti HJD were found to be catalase-negative when tested by the mixing of dilute hydrogen peroxide with thick cell suspensions.

\section{DISCUSSION}

The fermentative pattern of our strains of Fusobacterium nucleatum Knorr is essentially like that of the butyric acid bacteria except that the fusiform bacteria do not produce hydrogen. The fermentative pattern of the strains of Fusobacterium plauti-vincenti Knorr is like that of the homofermentative lactic acid bacteria.

A consideration of the metabolic patterns of these two groups of fusiform bacteria leads to the conclusion that the organisms are dissimilar. They are also dissimilar in their gram reactions and in the size of their cells. The similarity of these organisms lies in the shape of the cells, which have pointed ends, in their anaerobic nature, in their lack of catalase activity, and in their common habitat, the mouth.

From a consideration of the metabolic pattern, gram reaction, and catalase activity of $F$. plauti-vincenti HJD, one is led to the conclusion that it may be related to the homofermentative lactic acid bacteria of the genus Lactobacillus. There are certain differences, however, between $F$. plauti-vincenti and typical 
lactic acid bacteria. Firstly, the morphology of the two types of cells is different in that $F$. plauti-vincenti exhibits definitely pointed ends. This is not observed in the lactic acid bacteria or at least has not been described. This character is very convenient in the recognition of the organism but it may have no significance in determining the natural relationships. Secondly, $F$. plauti-vincenti takes the gram stain only under special conditions, whereas the lactobacilli are almost always strongly gram-positive. Thirdly, the tolerance to oxygen of the two groups of bacteria is somewhat different in that $F$. plauti-vincenti may be regarded as a strict anaerobe and the lactic acid bacteria are, in general, able to grow in the presence of air. It is true, however, that lactic acid bacteria vary greatly in their tolerance to oxygen and one, Lactobacillus bifidus, is reported as a strict anaerobe on primary isolation. Fourthly, a difference might be anticipated in dye sensitivity of the two groups of bacteria. $F$. plauti-vincenti is easily isolated on a medium containing gentian violet as an inhibitor of the growth of gram-positive organisms. It might be expected that the growth of lactic acid bacteria would be inhibited on this medium. Since the sensitivity of the lactic acid bacteria to the bacteriostatic properties of gentian violet is not known, the significance of the dye resistance of $F$. plauti-vincenti cannot be assessed.

The organism known as Fusobacterium nucleatum shows no close relationship to any well-studied group of bacteria. Certain similarities exist between its metabolic pattern and that of the clostridia producing a butyric acid fermentation (Barker, 1937; Woods and Clifton, 1937), but these similarities are small beside the great differences, both physiological and morphological, that exist between the two groups. Possibly members of the genus Bacteroides, the gram-negative, nonsporulating rods, sometimes with pointed ends, found in the intestine are related to $F$. nucleatum. Weiss and Rettger (1937) in their comprehensive study of the gram-negative, nonsporulating, anaerobic rods of the intestine found that the slender rods with pointed ends formed a group set apart from all the others by agglutinative, morphological, and cultural reactions. Bacteroides uncatus, Bacteroides vescus, and Bacteroides exiguus Eggerth and Gagnon are in this group. If the biochemical reactions of these organisms are compared with those of the fusiform bacteria, which they most closely resemble from the point of view of cellular morphology, the $F$. nucleatum and $F$. polymorphum group, it is seen that the intestinal inhabitants produce neither indole nor hydrogen sulfide and do not reduce nitrate, whereas the mouth inhabitants of similar morphology do all three. The intestinal inhabitants liquefy gelatin; the mouth inhabitants do not. A comparison of these biochemical characteristics, however, does not warrant any conclusions regarding the essential similarity or dissimilarity of the fermentative systems of these organisms.

Spaulding and Rettger (1937) also came to the conclusion that the two groups of fusiform bacteria are radically different. They were inclined to keep them in the same genus only because of the occurrence of intermediate types, that is, organisms that produced a low $\mathrm{pH}$ in carbohydrate medium and also reduced nitrates, or produced indole. It is questionable whether this evidence of overlapping in superficial characteristics warrants the common assemblage of organisms possessed of basically different fermentative patterns. 


\section{SUMMARY}

Fusobacterium nucleatum Knorr and Fusobacterium plauti-vincenti Knorr have very different fermentative patterns.

$F$. nucleatum decomposes both amino acids and carbohydrates by a modified butyric acid type of fermentation. The amino acids attacked most rapidly are serine, threonine, cystine, cysteine, lysine, histidine, tyrosine, and glutamic acid. The unsubstituted monoamino, monocarboxylic amino acids are not attacked when supplied individually, together, or with a readily fermentable substrate. Although glucose is not fermented rapidly, its presence in a complex medium greatly increases the cell yield.

$F$. plauti-vincenti catalyzes a simple lactic acid fermentation of glucose. Unlike $F$. nucleatum, it is unable to ferment amino acids. In the decomposition of pyruvate by cell suspensions the main products are carbon dioxide, formic acid, and acetic acid.

The difference between the metabolic patterns of the two groups of fusiform bacteria is so great that $F$. nucleatum Knorr (group I of Spaulding and Rettger) and $F$. plauti-vincenti Knorr (group II of Spaulding and Rettger) probably should not be included in the same genus. There are also slight differences in the gram reaction of the two organisms, as have been indicated earlier by other workers.

\section{REFERENCES}

BARKER, H. A. 1937 On the fermentation of glutamic acid. Enzymologia, 2, 175-182.

Bow, J. 1941 Fusobacterium. Studies on its bacteriology, serology, and pathogenicity. Norske Videnskaps-Akad. Oslo, I, Mat.-Naturv. Klasse, 9, 1-191.

Breed, R. S., Murray, E. G. D., and Hitchens, A. P. 1948 Bergey's manual of determinative bacteriology. 6th ed. Williams \& Wilkins Co., Baltimore. (5th ed., 1939 ; 4 th ed., 1934.)

Elliot, K., Benoy, M., and Baker, Z. 1935 The metabolism of lactic and pyruvic acids in normal and tumor tissues. Biochem. J., 29, 1937-1950.

Feigl, F., and Frehden, O. 1937 Nachweis von Glycerin. Microchim. Acta, 1, 137-138.

Friedemann, T. E., and Graeser, J. B. 1933 The determination of lactic acid. J. Biol. Chem., 100, 291-308.

Friedemann, T. E., and Haugen, G. E. 1943 Determination of keto acids in blood and urine. J. Biol. Chem., 147, 415-442.

HAssid, W. Z. 1937 Determination of sugar in plants by oxidation with ferricyanide and ceric sulfate titration. Ind. Eng. Chem., Anal. Ed., 9, 228-229.

Hozlling, A. 1910 Die Kernverhältnisse von Fusiformis termitidis. Arch. Protistenk., 19, 239-245.

Knetemann, A. 1928 The Duclaux method for the estimation of volatile acids and its application to the estimation of butter fat in margarine. Rec. Trav. Chim., 47, 950 970.

KNORR, M. 1922 Uber die fusispirillare Symbiose, die Gattung Fusobacterium (K. B. Lehman) und Spirillum sputigunum. Die Gattung Fusobacterium. Zentr. Bakt. Parasitenk., I, Orig., 87, 536-545.

Langlykke, A. F., and Peterson, W. H. 1937 Determination of acetyl-methyl-carbinol. Effect of certain analytical procedures. Ind. Eng. Chem., Anal. Ed., 9, 163-166.

Northrop, J. H., Ashw, L. A., AND Senior, J. K. 1919 Biochemistry of Bacillus acetoethylicum with reference to the formation of acetone. J. Biol. Chem., 39, 1-21.

Peters, J., and van Slyke, D. D. 1932 Quantitative clinical chemistry. II. Methods. Williams \& Wilkins Co., Baltimore. 
Schicktanz, S. J., Stegle, W. I., aNd Bharsdell, A. C. 1940 Analysis of mixtures of aliphatic acids. Ind. Eng. Chem., Anal. Ed., 12, 320-324.

Slanetz, L., and Retrger, L. F. 1933 Systematic study of fusiform bacteria. J. Bact., 26, 599-620.

Spadlding, E. H., and Rettger, L. F. 1937 a Fusobacterium genus. I. Biochemical and serological classification. J. Bact., 34, 535-548.

Spaulding, E. H., and Rettger, L. F. $1937 b$ Fusobacterium genus. II. Some observations on growth requirements and variation. J. Bact., 34, 549-564.

Topley, W. W. C., and Wrlson, G. S. 1946 Principles of bacteriology and immunity. 3d ed. Williams \& Wilkins Co., Baltimore.

VARnet, P. L. 1927 The serological classification of fusiform bacilli. J. Bact., 13, 275314.

Weinberg, M., and Prevot, A. 1926 Recherches sur les floremicrobienne del'appendicite. Fusobacterium biacutum (n.sp.). Compt. rend. soc. biol., 95, 519-522.

Weiss, J. E., AND RetTaER, L. F. 1937 The gram-negative bacteroides of the intestine. J. Bact., 33, 423-434.

Woods, D. D., AND Clifton, C. E. 1937 Hydrogen production and amino acid utilization by Clostridium tetanomorphum. Biochem. J., 31, 1774-1788. 